\title{
Midwife observations on the impact of hot weather on poor perinatal outcomes in central Australia: a qualitative study
}

\begin{tabular}{|c|c|}
\hline $\begin{array}{c}\text { Supriya Mathew' } \\
\text { College of Medicine and Public Health, } \\
\text { Centre for Remote Health } \\
\text { Flinders University } \\
\text { Supriya.Mathew@flinders.edu.au }\end{array}$ & $\begin{array}{c}\text { Deepika Mathur } \\
\text { Northern Institute, } \\
\text { Charles Darwin University } \\
\text { Deepika.Mathur@cdu.edu.au }\end{array}$ \\
\hline Elizabeth McDonald & Anne B Chang \\
Menzies School of Health Research & Menzies School of Health Research \\
Elizabeth.McDonald@menzies.edu.au & Anne.Chang@menzies.edu.au \\
\hline \multicolumn{2}{|c|}{ Rolf Gerritsen } \\
Northern Institute, Charles Darwin University \\
Rolf.Gerritsen@cdu.edu.au
\end{tabular}

Keywords: preterm birth; stillbirth; extreme heat; Indigenous women

\begin{abstract}
Remote arid Australian towns already experience high summer temperature and are projected to have warmer future temperatures due to climatic changes. It is also home to many Indigenous women who prefer an outdoor lifestyle and have poor perinatal outcomes. Quantitative analysis of preterm birth and temperature data indicated higher risks to preterm births among Indigenous women in central Australia. This paper aims to report midwives' observations on the effects of hot weather on poor perinatal outcomes in a central Australian town. Semi-structured interviews were conducted with 12 registered midwives providing perinatal services to families in central Australia. The interview responses were coded and classified against the major themes. None of the midwives perceived any direct relationship between heat exposure and preterm birth, but reported increased incidences of dehydration, exhaustion, discomfort and requests for induction among pregnant women which were often treated before further complications. A quarter of the respondents also mentioned that Indigenous pregnant women do not complain, even when symptoms of heat stress are evident. Quantitative analysis of perinatal and temperature data indicated increased risks to preterm births, but did not provide information on discomfort, dehydration, exhaustion or more requests to be induced. The study also shows that it is important for midwives and health practitioners to be culturally-sensitive to the fact that certain population groups tend not to complain, even if they are experiencing symptoms of heat stress. This research highlights the importance of cultural training for midwives and their role in alerting pregnant women to take precautionary measures during summer periods.
\end{abstract}

\section{Introduction}

Poor perinatal outcomes such as stillbirths (baby born with no signs of life at or after 28 weeks' gestation) and preterm births (births before completing 37 weeks of gestation) often lead to economic costs and stress on families (Trasande et al., 2016; Ten Hoope-Bender et al., 2016; Petrou et al., 2001). Pre-term 
births were one of the leading causes of death among children under the age of 5 years (WHO, 2016a). Globally, for every 1000 births, around 18 babies were still born in 2015 (WHO, 2016b). Preterm infants are likely to experience short and long term health problems and even permanent disability (Petrou et al., 2001; Wen et al., 2004; Soilly et al., 2014). Despite improved antenatal programs and access to technology to monitor pregnancy, the incidence of poor pregnancy outcomes such as preterm births have risen globally in the past two decades (Blencowe et al., 2012). While preterm births are highest in low income countries (Beck et al., 2010), such risks are also quite high among Indigenous populations in high income countries such as Australia, Canada and the United States (Shah et al., 2011; Heaman et al., 2005). In Australia, the rate of Indigenous preterm birth and perinatal mortality is nearly double that of the non-Indigenous population making it important to understand factors that may influence such poor perinatal outcomes (AlHW, 2016b; AlHW, 2017).

Several risk factors have been linked to preterm births, low birth weights and stillbirths. Maternal characteristics (e.g. age), maternal medical conditions (e.g. overweight, diabetes, high blood pressure), maternal reproductive history (personal or family history of preterm birth, previous preterm births or miscarriages) and general maternal health (nutritional status, infection and chronic disease, e.g. diabetes and hypertension) include some of the risk factors (AlHW, 2016a; AlHW, 2017; AlHW, 2016b; Goldenberg et al., 2008; Flenady et al., 2011). Certain fetal characteristics such as multiple pregnancies, small for gestation age and growth restriction also contribute towards poor perinatal outcomes (AlHW, 2016a; AlHW, 2017; AlHW, 2016b).

Other risk factors include social factors such as low education, domestic violence, poor socio-economic conditions (Negger et al., 2004; Chiavarini et al., 2012), Indigeneity (e.g. 16\% preterm births compared to $6 \%$ preterm births for non-Indigenous Australian mothers) and access to antenatal care (e.g. living in very remote locations or locations with low access to antenatal care) (AlHW, 2016a; AlHW, 2017; AlHW, 2016b, Goldenberg et al., 2008). Exposure to environmental variables such as extreme temperature, humidity, ozone, carbon monoxide, nitrous oxide and particulate matter (Trasande et al., 2016; Strand et al., 2011a; Basu et al., 2010; Dadvand et al., 2011; Flouris et al., 2009; Zhang et al., 2017; Wang et al., 2013) and certain lifestyle choices such as use of alcohol and other drugs (Flenady et al., 2011; Varner et al., 2014) also contribute to poor perinatal outcomes.

A few Brisbane based studies have explored the impact of ambient temperature (Strand et al., 2011b; Li et al., 2018) and heat waves (Wang et al., 2013) and identified increased preterm birth risks. Another study in arid Australia indicated statistically significant increase in risks of preterm births due to exposure to extreme maximum temperature $\left(>41^{\circ} \mathrm{C}\right)$ during the last 3 weeks of pregnancy (Mathew et al., 2017). Environmental risk factors such as exposure to extreme heat and its impact on perinatal outcomes have been under-researched in Australia. All the existing Australian studies exploring the association between heat exposure and perinatal outcomes used hospital level health record data. The studies did not collect place-based data or explore the impact of temperature exposure on less severe heat related health symptoms such as dehydration or tiredness. This paper focuses on the same geographical area as Mathew et al. (2017) and aims to explore further the issue using midwives' observations on the effects of hot weather on poor perinatal outcomes. Specifically, the paper explores the following research questions: What impacts of heat are observed among pregnant women in a central Australian town? What are the factors that might be contributing towards the impact? Do the observed impacts differ for specific groups of the population?

\section{Data and methods}

\section{Study design and data collection}

Quantitative data was analysed in the initial stage of the research (Mathew et al., 2017). The quantitative study was conducted using birth and perinatal outcome data for the central Australian hospital which was accessed from the Northern Territory (NT) Midwives Data Collection (available from the Northern Territory Department of Health, Health Gains Planning branch) and temperature data sourced through the Bureau of Meteorology (BoM). This qualitative study was sequentially planned to examine 
if midwives practising in the central Australian hospital observed increased preterm births or other poor perinatal outcomes such as stillbirth and or any other heat related stress due to temperature exposure and whether it was higher among any specific groups of the population. Heat related stress could be observed in the form of more antenatal visits, discomfort, dehydration, requests for induction (artificial start of the birth process through medical interventions or other methods), elective caesarean or miscarriages (Rylander et al., 2013), none of which have been explored in the quantitative study using the NT midwives' data collection.

The interview questions in this study were targeted to understand three main objectives: Objective 1: What impacts of heat are observed among pregnant women in the central Australian town? Objective 2: What are the factors that might be contributing towards the impact? Objective 3: Do the observed impacts differ for specific groups of the population? The interview questionnaire was pilot tested with two central Australian health researchers with nursing and midwifery background.

\section{Ethics}

Ethics approval (reference number HREC-15-326) to access the NT Midwives Data Collection and to conduct the interviews was obtained from the Central Australian Human Research Ethics Committee (CAHREC).

\section{Study site}

The Central Australian service town was chosen as it has (i) an arid climate with high summer temperatures (average of monthly summer maximum temperatures $>35^{\circ} \mathrm{C}$ ) (see Figure 1), (ii) high proportion of Indigenous population (18\%) (ABS, 2016) who are more exposed to the outdoor environment due to their preferred way of living, (iii) future warmer atmospheric projections (e.g. days with temperature $>40^{\circ} \mathrm{C}$ will nearly double by 2030 for a mid-range greenhouse gas emission scenario; Webb et al., 2015). The town also has the major secondary referral hospital for central Australia, with 186 beds and serving up to 60,000 people including visitors to the region. The hospital covers a catchment area of approximately 1.6 million square kilometres and supports people residing in the Northern Territory and also in remote communities in northern South Australia and in the south west of Western Australia. In 2013 (which is the latest data available through the NT midwives data collection) there were 713 births in the hospital, $50 \%$ of the births were Indigenous of which more than $60 \%$ were non-residents of the town. 
Figure 1: Monthly variation of mean maximum temperatures at the Alice Springs airport BoM weather station

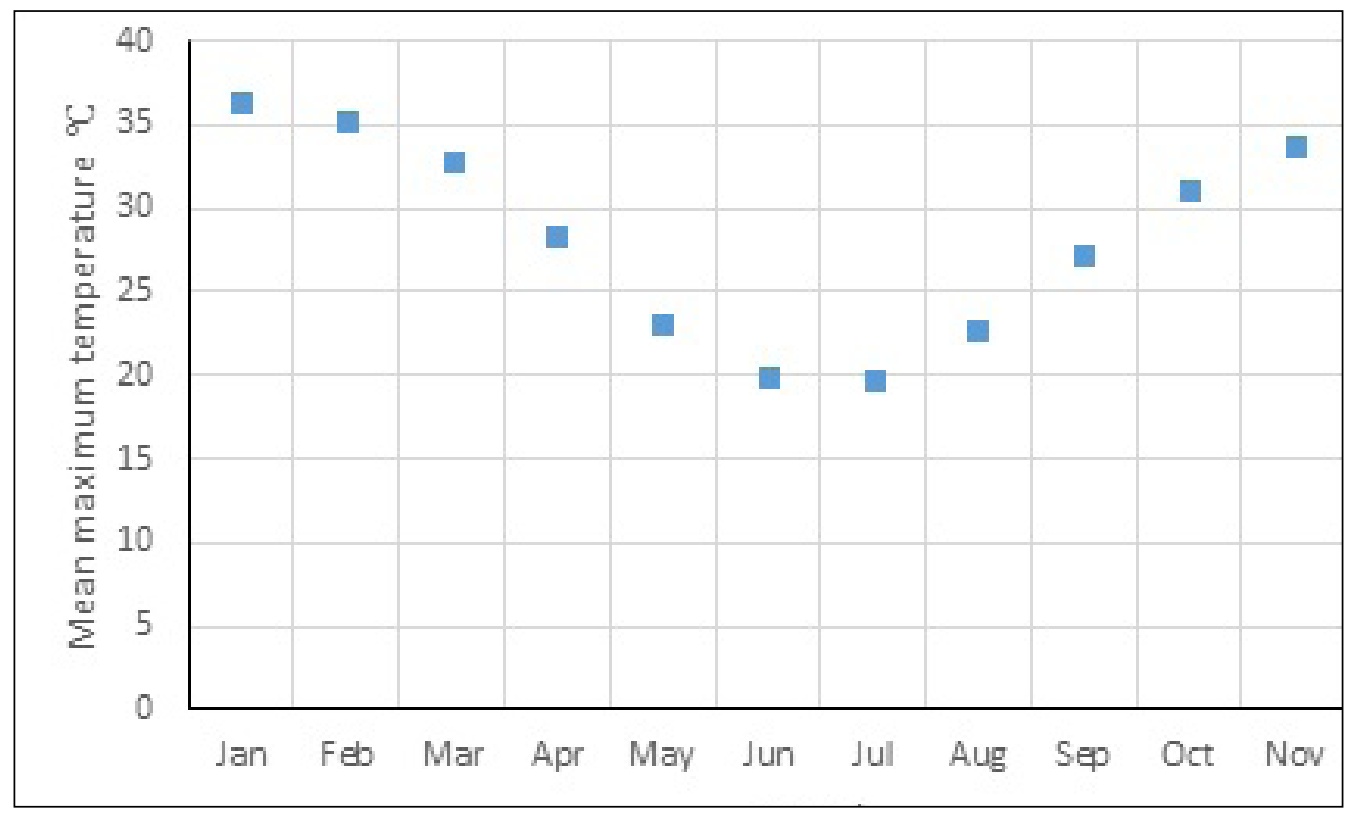

Source: BoM, n.d.

\section{Participants \& recruitment}

Registered midwives providing perinatal services to families in the central Australian town were interviewed using a semi-structured questionnaire (interview questions in table 1 Appendix). A list including the names and contacts of 23 midwives were provided by the hospital and they were invited to participate in the interview. Twelve midwives provided informed written consent and attended appointments to be interviewed $(\mathrm{N}=12)$; another four replied to the request for interview but declined to participate; three others responded but as they had only recently moved to the central Australian town they were not interviewed; and no response was received from four midwives despite more than one request made for interview consent and suitable time. The response rate was $60 \%$ (12/20) after excluding the three midwives who had recently moved to town from the total number of midwives. A higher response rate was not attained primarily because shift work and rostering issues made it difficult for midwives to identify a suitable time to be interviewed, and not all midwives checked their work email on a regular basis, which made communicating with them difficult.

Midwives were considered as the main respondents for the interviews, as they could be considered as 'experts' based on their experience in antenatal care. Midwives working at both the public hospital and the local community-based Midwifery Group Practice (MGP), which is also part of the hospital were invited for interviews. Participation in the interviews were restricted to midwives who had at least a year of experience working in central Australia. This selection criterion was important as there is usually a large staff turnover in remote communities (Russel et al., 2017) and many new midwives may not have sufficient contextual experience working with pregnant women in central Australia. At least $60 \%$ participation by the eligible midwives was targeted. A $60 \%$ response rate is considered sufficient to reach data saturation, after which no new information arises despite continuing data collection (Morse et al., 2002). The interviews were conducted by a local female researcher experienced in conducting qualitative research. All the midwives who participated were female. The interviews took a maximum of 15 minutes and were conducted during breaks of work time and after work shifts. Interview responses were audio recorded and transcribed. Interview notes were also taken by the interviewer and summarised to the respondent at the end of the interview. While the interviewer was aware of the results of the quantitative analysis, care was taken not to mention the results to the respondents and create any bias. A quick summary of the response was provided to validate the data and encourage the respondents to 
add any further information. It also helped the researcher to understand if additional interviews were to be conducted to test whether the themes and categories were sufficient. Data saturation was observed by the researcher conducting the interview after nearly 8 interviews. To maintain the anonymity of the respondents, the interview responses were numbered and only the numbers are quoted in this paper.

\section{Data analysis}

Actual interviews were conducted between 2016 December and 2017 March. The collected responses were coded by both the first and second author. After coding, the authors checked for commonalities between the codes, relationships and differences across the data set, and identified the major themes (Gibsen and Brown, 2009).

\section{Results}

There were 7973 births including both live and still births during the period 2003 to 2013 . The data included 87 stillbirths and almost $67 \%$ of the stillbirths were Indigenous. There were 7942 singular livebirths (number of Indigenous births=4194; number of non-Indigenous births=3748; preterm births=809; number of Indigenous preterm births $=547$ and number of non-Indigenous preterm births $=262$; total number of inductions=2035; number of inductions for Indigenous women=1123; number of inductions for non-Indigenous women=912; total number of elective caesarean=816, number of elective caesarean for Indigenous women=380; number of elective caesarean for non-Indigenous women=436; number of elective caesarean before full term (i.e. $<40$ weeks=713)) during the period 2003-2013.

The number of preterm births per total births peaked during the summer months of November, December and January and was lowest during the months of September and October (see Figure 2a). The preterm birth to total birth ratio was higher for the Indigenous births compared to the non-Indigenous births (see Figure 2b-ca) The preterm birth ratio for Indigenous births was highest in January and lowest in September and October (see Figure 2b). The ratio for non-Indigenous births was highest in December and lowest in September and October (see Figure 2c). There was a total of 2035 inductions during the period 2003-2013. The peak number of inductions per total live births did not coincide with the hotter months (See Figure 3a). It was highest in May and lowest during March and June. The induction ratios for Indigenous births were highest in February and November and lowest in June and July (see Figure $3 b)$. The induction ratios for non-Indigenous births peaked in May and June, but was lowest in March and September (see Figure 3c).

Figures 2a-c: Variation in the a) number of preterm births (PTBs) per total singular live births; b) number of Indigenous preterm births per total singular live Indigenous births; c) number of nonIndigenous preterm births per total singular live non-Indigenous births across months using the NT midwives data collection for the period 2003-2013; Error bars show standard error. 

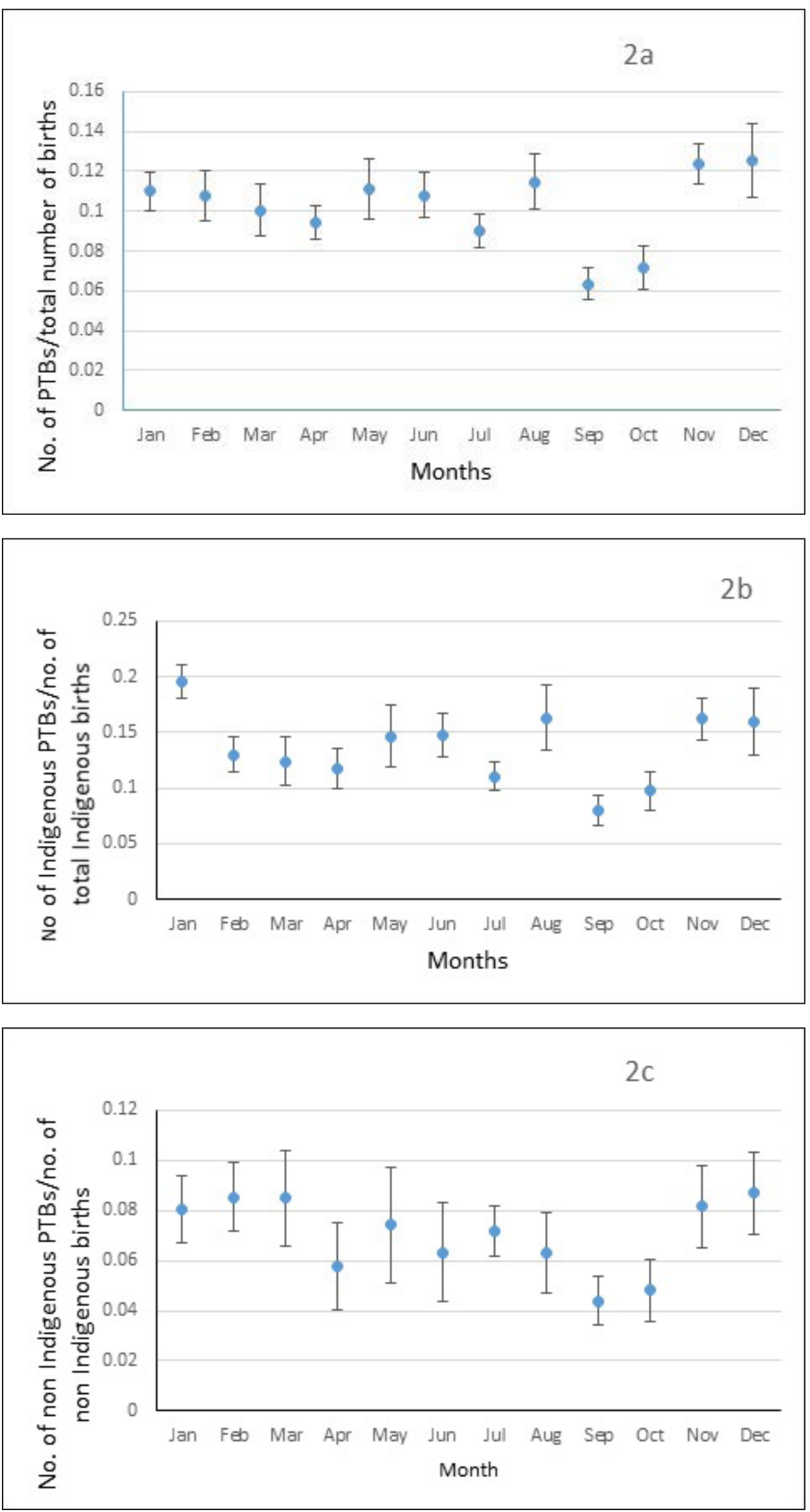
Figures 3a-c: Variation in the number of a) induced births per total births; $b$ ) induced Indigenous births per total Indigenous births; c) induced non-Indigenous births per total non-Indigenous births across months using NT midwives data collection for the period 2003-2013.
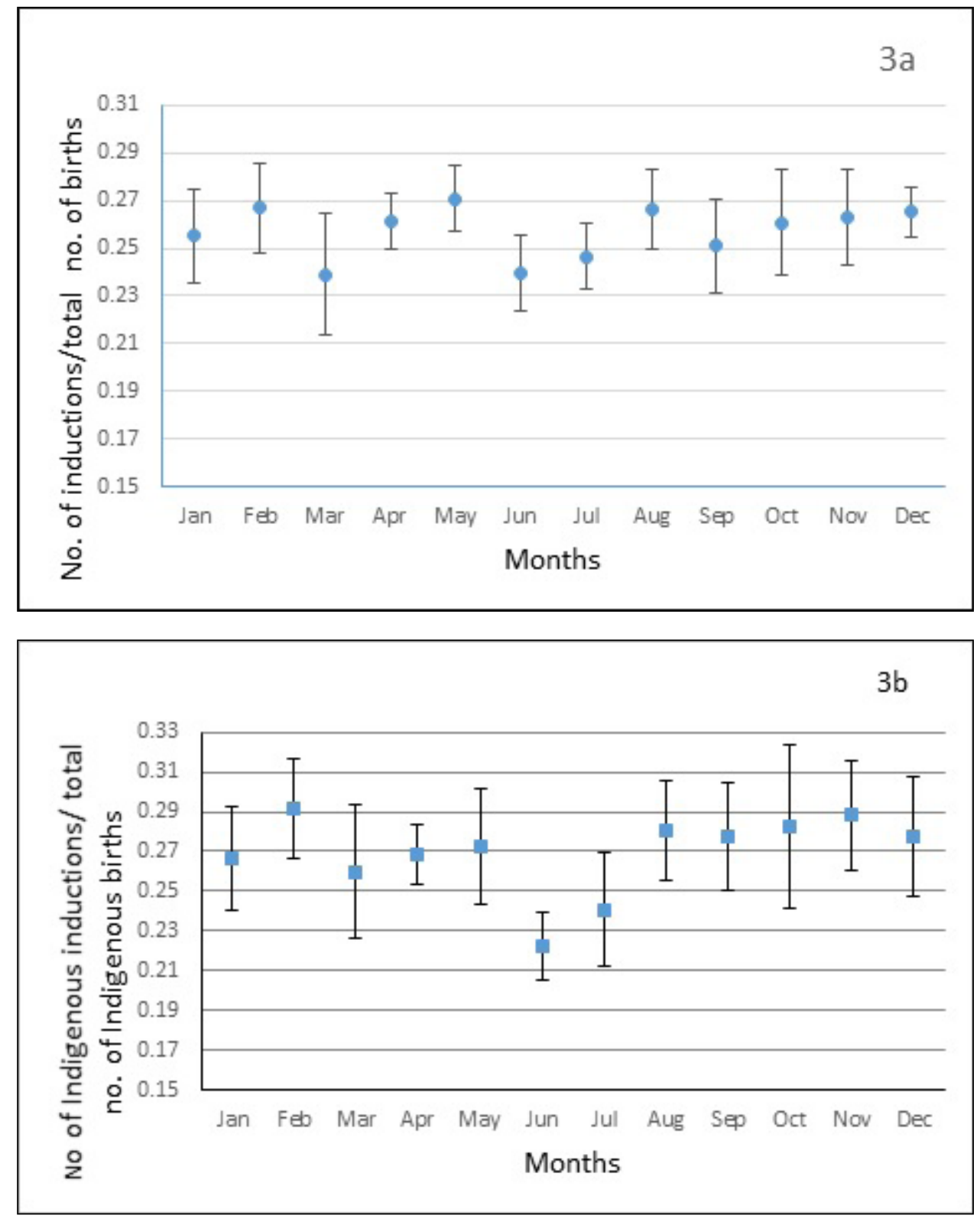


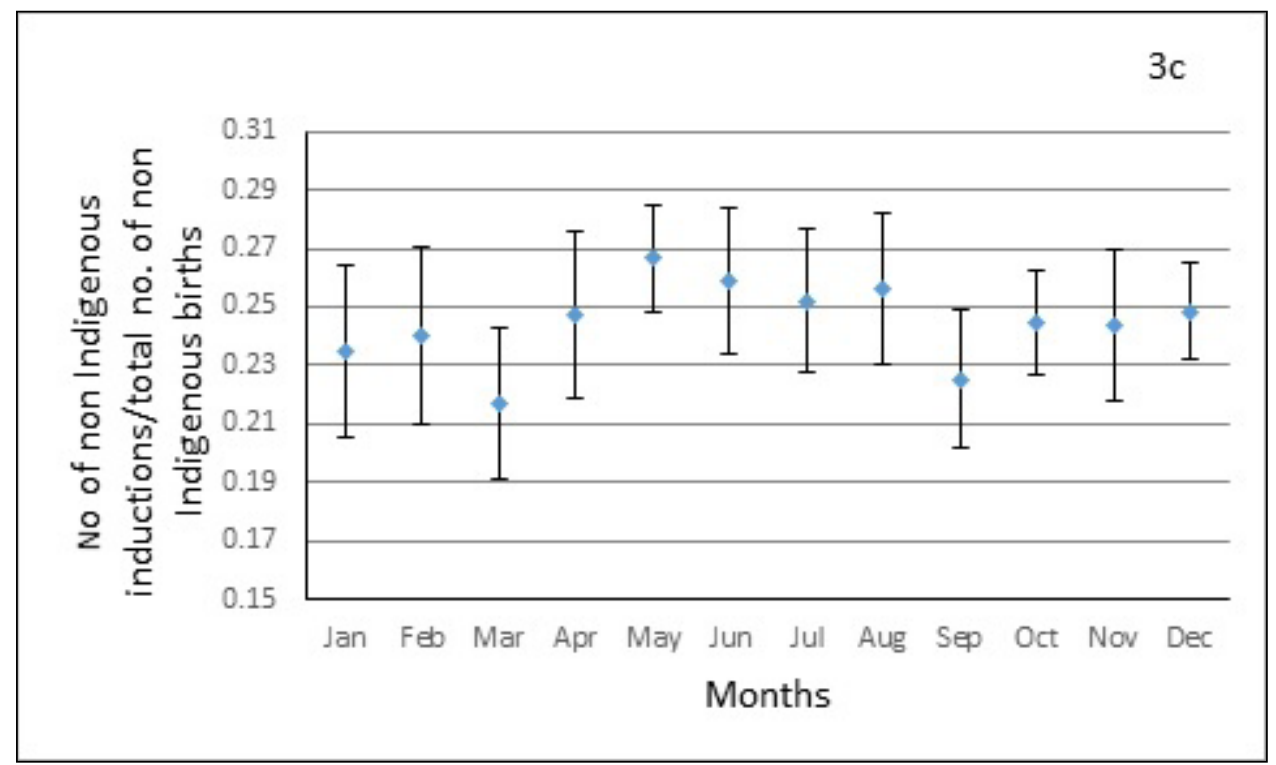

The results of the semi-structured interviews are discussed mainly using two major themes: i) impacts of hot weather and ii) vulnerability of Indigenous pregnant women to hot weather.

\section{Impacts of hot weather exposure on pregnant women in an arid central Australian remote town}

There is no universal definition for hot weather or extended period of hot days usually termed as 'heatwaves'. Temperature thresholds for health effect studies are often dependent on a location's climate (arid, tropical climate), health outcomes studied (e.g. cardiovascular risks, mental health illness) and the population (e.g. elderly, pregnant women) considered. The temperature threshold values midwives perceived to be 'extreme heat' in central Australia ranged from 'anything over $35^{\circ} \mathrm{C}$ ' to over $40^{\circ} \mathrm{C}$. More than a quarter of the midwives highlighted that pregnant women felt the heat more, but the perception of heat could be dependent on the individual. One midwife stated:

\section{$38^{\circ} \mathrm{C}$ is hot. If you are pregnant you feel the heat more. (midwife 1, hospital)}

Responses related to the effects of extreme heat were mainly linked to heat stress rather than poor perinatal outcomes. Two respondents acknowledged that heat would cause a stress on the body but had not observed whether it had any direct impact on birth outcomes.

It is just another stress on the body. As soon as you get stress on the body, you can get premature labour or premature babies or stillbirths I guess. It is an added stress on the body. You can't say to someone who is coming in with a miscarriage that you had that because of the heat. There are just too many factors, so this would be just something added to the mix. But because I have not done such a research I couldn't say for sure. (midwife 2, hospital)

Two of the midwives indicated that they had noted more miscarriages during summer, with one of the midwives mentioning the month of January as particularly bad. None of the respondents reported that they had observed any direct link between days when the temperature was very high and preterm births. They agreed that theoretically very hot weather could lead to heat stress and the onset of labour but they had not experienced this or even thought about it. One midwife rejected the concept outright:

I don't think I have noticed any direct correlation. I have seen a number of preterm births here- not much difference in summer and winter. (midwife 3, hospital)

Another midwife stated that pre-term births could happen if timely measures or medical interventions are not taken. Her response: 
Hard to say (link between extreme heat and preterm birth), if the women and baby are tachycardic that way we might take measures and if that doesn't settle we might have to induce her. That might cause a cascade of things. If she is really not ready then the induction might end up in an emergency caesarean. So though that's not proven, I can see that happening. (midwife 4, hospital)

Responses by midwives to the questions concerning the effects of extreme ambient heat on the pregnancy outcomes revealed dehydration as the most pertinent effect. One midwife described a heat stress impact as follows:

Dehydration would be the big one. Many women come in with dehydration. They are probably used to that level of dehydration. The women are chronically dehydrated most of the time. When they come in and we put in a CTG trace on, often the baby is tachycardic. So that affects the interventions that we have to do for the baby sometimes or the mum. We sometimes have to rehydrate women. It increases in the summer months definitely. (midwife 2, hospital)

Another midwife described a situation of dehydration where intervention was required:

I have certainly seen that if a woman is (physically) active during the hot time, for example, I had a woman walk from the other side of town in one morning, she was tachycardic. Her heart rate was very high, she was very dry. The baby had a very high heart rate as well. There was probably not an impact on the birth. We took measures to correct this. We had to cannulate her with intravenous fluids. (midwife 4, hospital)

Two midwives mentioned that due to dehydration, pregnant women could get urinary tract infections (UTI) which could in turn lead to preterm labour. The other impact of hot weather mentioned by more than half of the respondents was that it causes discomfort to pregnant women. They highlighted that high ambient temperatures in summer, increase in body weight and the rise in body temperature that normally occurs in pregnancy could create a great deal of discomfort among pregnant women. Midwife responses indicated higher discomfort during summer months often resulted in more pregnant women requesting induction:

There is pattern of women wanting induction. Heat is so horrendous to cope and they want the baby out. (midwife 5, Midwifery Group Practice)

Definitely discomfort. Often women are so sick of the heat they ask to be induced. (midwife 6 , hospital)

In addition to discomfort, exhaustion among pregnant women during summer months was also mentioned by three midwives as another direct impact of heat. Older women and mothers who had other children to look after were perceived to experience exhaustion the most.

Women with other children feel more tired during the hot periods since they are pregnant and need to look after the children too. (midwife 7, hospital)

One midwife from the Midwifery Group Practice reported that it was difficult to estimate how many pregnant women suffered from dehydration and were treated for preterm labour. Once they returned home after being treated by the midwives/doctors and had their baby on the due date, this episode might not reflect in the NT Midwives data collection (data set available from the NT department of health which is often used for research purposes). This was supported by another midwife's response at the hospital.

Often when the women comes in on a hot day thinking she is in labour. But after cooling down and hydrating she goes back. (midwife 6, hospital) 


\section{Vulnerability of Indigenous pregnant women to hot weather and measures}

Majority of the midwives mentioned that they do advise women to rest more, involve in less strenuous activities, hydrate themselves and to stay indoors during the hotter times of the day during summer months. Most midwives (i.e. 9 out 12) who responded to the question concerning extreme heat events and the effects they perceived to occur for Indigenous and non-Indigenous women, highlighted that Indigenous women, do not complain about the heat. One of the midwives mentioned:

It is amazing what the Indigenous women put up with. When some of them come in we are amazed - how are you not thirsty, how are you not hot! They don't complain. They are brilliant, so easy to look after. (midwife 2, hospital)

Another midwife reiterated the same by highlighting that Indigenous woman were usually quiet about any discomfort unless specifically asked about the specific issue:

I experienced that Indigenous girls don't complain that much. Perhaps if they are asked they would, but they don't volunteer that information readily. (midwife 7, hospital)

Interestingly, some midwives commented that the number of births because of induction of labour increased due to extreme heat events. The issue of access to cooling technology was also referred by a midwife who said:

The Indigenous women tend not to complain. You really need to look what's going on. You can see that they are hot; you can see that they are dry. Don't have an air conditioned house. They mostly feel the effects but they don't tell us as well. (midwife 4, hospital)

\section{Discussion}

While quantitative analysis of the NT midwives' data collection indicated increased risks to preterm births due to extreme temperature exposures, in this qualitative study, midwives did not observe a direct relationship between preterm births and hot weather. In contrast, the preterm birth per total birth ratio were higher for the hotter months and the ratio was lowest for the months of September and October (see Figures 2a-c). The midwives agree that heat exposure could result in stress that could potentially result in preterm births. The quantitative study examined the impacts on preterm births only. Other potential issues such as stillbirth, discomfort, dehydration, requests for induction, miscarriages, and requests for caesareans could not be analysed due to limited data. While the midwives did not directly associate extreme heat with preterm births, their responses suggest that dehydration, discomfort and exhaustion because of extreme heat events could lead to poor perinatal outcomes. Also, several midwives thought that heat exposure triggered requests for induction, though this was not clearly evident in the NT midwives' data collection for total births (Figures 3a). It could be that the induction requests were higher during summer months, but pregnant women were treated for their discomfort rather than induced. This would mean the actual number of induction requests would be different from the actual number of pregnant women induced per total births which is the variable available from the NT midwives data collection. Induction ratios for Indigenous births were highest for the hot months of November and February and lowest for the months with lowest mean maximum temperatures. The spike in February for total inductions and Indigenous inductions could potentially be a lagged effect of summer time temperature exposure and the spike in May could be due to exposure to sudden temperature differences (Figures 3a-3b). Further investigation of the NT midwives data as well as more information on the adaptive responses of Indigenous and non-Indigenous people are required.

Anecdotal information provided by those interviewed suggested that pregnant women frequently become dehydrated during extreme heat events. However, there are no mechanisms in place to measure how big a problem this in remote arid towns of central Australia. For example, there is no data available that links temperature to dehydration among pregnant women that could be analysed for any statistical significance. Also, from the interview data or the NT midwives data collection, we cannot ascertain with any accuracy the proportion of Indigenous as opposed to non-Indigenous pregnant women who are 
presented with symptoms of dehydration. This also means that, while the quantitative study by Mathew et al. (2017), explores the impact of high temperature on preterm births in the central Australian town, the potential heat impacts could be underestimated by the fact that many cases are treated medically well before it results in preterm births.

Most midwives interviewed indicated that Indigenous pregnant women did not complain about heat related discomfort even when the symptoms of heat stress were evident to the midwives. The lack of communication by Indigenous pregnant women may be cultural and highlights the importance of cultural training in such areas for less experienced midwives and health professionals treating Indigenous pregnant women. The communication gap between health professionals and Indigenous Australians could be caused by cultural and linguistic differences and differences in worldviews (Amery, 2017). This study did not interview newly appointed midwives to explore if they were aware of the issue. The low level of communication by Indigenous pregnant women during regular antenatal appointments could be one of the factors contributing to the high preterm birth rates. Studies also indicate that Indigenous people often respond after a period of silence to questions (Amery, 2017). Health professionals both Indigenous and non-Indigenous need to be sensitive to the fact that Indigenous pregnant women can be less vocal or may take a period of prolonged silence to describe the consequent discomfort, dehydration and exhaustion they experience during summer periods.

Midwives also pointed out that Indigenous women living in and around the central Australian town and further away in remote communities may not have adequate access to appropriate cooling technologies. Research already indicates that energy poverty is emerging among Indigenous communities (Race et al., 2016; Race et al., 2017) and this could affect the capacity of Indigenous communities to afford energy-intensive cooling mechanisms. Often the cooling technologies installed in town camps do not suit the cultural or life style practices of Indigenous communities affecting proper use of measures used to moderate outside temperatures (Race et al., 2016). Indigenous pregnant women from remote areas are requested to move to the nearest central Australian town or the nearest public hospital closer to the birth date. Indigenous women who are in such 'sit down' periods are likely not to have adequate access to transport, their usual social networks and may need to walk on hot days to the hospital or to access other services.

The findings from the interviews highlight the need for further place-based research to understand the impact of exposure to extreme heat on pregnant women. It also underlines the importance of qualitative information such as midwife expert observation or midwife diaries, to complement statistical analysis of birth data. Most quantitative studies exclude induced labour and requests for caesarean while exploring the relationship between heat and perinatal outcomes, but requests for inductions or caesareans could be a direct impact of the discomfort and exhaustion caused by heat. The potential effects of extreme hot periods need to be further understood to prepare health guidelines and educate midwives and emergency care nurses/professionals who are usually the first point of contact outside regular antenatal appointments. In Australia, in addition to the study by Mathew et al. (2017), Brisbane based studies have explored the impact of ambient temperature (Strand et al., 2011b; Li et al., 2018) and heat waves (Wang et al., 2013) and identified increased preterm birth risks. These studies have also relied on preterm birth count data, but not on any observations that may have been recorded by midwives. The current qualitative study is limited by the fact that it includes only a sample of midwives practicing in the central Australian hospital and thus the results cannot be generalised for the region. The scope of the study could have been enhanced by conducting interviews with obstetricians, emergency care nurses or remote clinic nurses in central Australia.

\section{Conclusions}

This study points towards the need of antenatal care guidelines relevant for specific climate zones and sensitive to the cultural requirements of pregnant women especially because there are usually high staff turnover in remote hospitals and clinics. The role of Indigenous language and cultural interpreters are also important during treatment. Midwives did not observe any direct risks to preterm births in contrast to the peaks observed in the summer period using the NT midwives data collection and the higher risks reported by three other Australian studies. This highlights the need for further studies to understand 
if there is a requirement to create more awareness on the potential heat related effects on pregnant women among midwives. The size of the problem of heat related discomfort, exhaustion or dehydration among pregnant women cannot be quantified, however, anecdotal information indicates the problem is not uncommon. Studies that explore the impacts of heat should thus use a combination of perinatal data usually collected for statistical purposes combined with antenatal notes or midwife observations. There needs to be a greater emphasis on educating both Indigenous and non-Indigenous pregnant women to reduce extreme heat exposure and on taking steps to minimise the effects of extreme hot weather events. These include avoiding exertion, and having easy access to good quality drinking water and availing cool places to rest.

\section{Acknowledgements}

We would like to thank the General Manager at the central Australian hospital, the midwives interviewed and the Northern Territory Department of Health for data access. This research was conducted using funds from Charles Darwin University's internal research grant. 


\section{References}

Amery, R. (2017). Recognising the communication gap in Indigenous health care. Med J Australia, 207(1), 13-15. doi: 10.5694/mja17.00042

ABS (Australian Bureau of Statistics). (2016). Census Quick Stats. Retrieved from http://www.abs.gov. $\mathrm{au} /$ websitedbs/censushome.nsf/home/quickstats?opendocument\&navpos $=220$

AlHW (Australian Institute of Health and Welfare). (2016a). Australia's mothers and babies 2014-in brief. Perinatal statistics series no. 32. Cat no. PER 87. Canberra: AlHW. Retrieved from https://www. aihw.gov.au/getmedia/68429bae-ebcd-4edb-9861-73d5fbdc258c/20210.pdf.aspx?inline=true

AlHW. (2016b). Perinatal deaths in Australia, 1993-2012. Perinatal deaths series no. 1. Cat. no. PER 86. Canberra: AlHW. Retrieved from https://www.aihw.gov.au/getmedia/7cd62505-c674-4926-8035b879c009f5e3/19440.pdf.aspx?inline=true

AlHW. (2017). Australia's mothers and babies 2015-in brief. Perinatal statistics series no. 33. Cat no. PER 91. Canberra: AIHW. Retrieved from https://www.aihw.gov.au/getmedia/728e7dc2-ced647b7-addd-befc9d95af2d/aihw-per-91-inbrief.pdf.aspx?inline=true

Basu, R., Malig, B., \& Ostro, B. (2010). High ambient temperature and the risk of preterm delivery. American Journal of Epidemiology, 172, 1108-1117.

Beck, S., Wojdyla, D., Say, L., Betran, A. P., Merialdi, M., Requejo, J. H, Rubens, C., Menon, R., \& Van Look, P. F. (2010). The worldwide incidence of preterm birth: a systematic review of maternal mortality and morbidity. Bull World Health Organ, 88(1), 31-38. doi:10.2471/blt.08.062554

Blencowe, H., Cousens, S., Oestergaard, M. Z., Chou, D., Moller, A. B., Narwal, R., ... Lawn, J. E. (2012). National, regional, and worldwide estimates of preterm birth rates in the year 2010 with time trends since 1990 for selected countries: a systematic analysis and implications. The Lancet, 379, 2162-2172. doi: 10.1016/S0140-6736(12)60820-4

BoM (Bureau of Meteorology). (n.d.). Climate data for Alice Springs. Retrieved from http://www.bom.gov. au/climate/averages/tables/cw_015590.shtml

Chiavarini, M., Bartolucci, F., Gili, A., Pieroni, L., \& Minelli, L. (2012). Effects of individual and social factors on preterm birth and low birth weight: empirical evidence from regional data in Italy. International Journal of Public Health, 57(2), 261-268. doi:10.1007/s00038-011-0311

Dadvand, P., Basagaña, X., Sartini, C., Figueras, F., Vrijheid, M., De Nazelle, A., ... Nieuwenhuijsen, M. J. (2011). Climate extremes and the length of gestation. Environmental health perspectives, 119, 1449-1453. doi: 10.1289/ehp.1003241

Flenady, V., Koopmans, L., Middleton, P., Frøen, J. F., Smith, G. C., Gibbons, K., ... Ezzati, M. (2011). Major risk factors for stillbirth in high-income countries: a systematic review and meta-analysis. The Lancet, 377, 1331-1340. doi: 10.1016/S0140-6736(10)62233-7

Flouris, A. D., Spiropoulos, Y., Sakellariou, G. J., \& Koutedakis, Y. (2009). Effect of seasonal programming on fetal development and longevity: links with environmental temperature. American Journal of Human Biology, 21, 214-216.

Gibsen, W., \& Brown, A. (2009). Working with qualitative data. London, England: SAGE Publications, Ltd.

Goldenberg, R. L., Culhane, J. F., lams, J. D., \& Romero, R. (2008). Epidemiology and causes of preterm birth. The Lancet, 371, 75-84. doi: 10.1016/S0140-6736(08)60074-4

Heaman, M. I., Blanchard, J. F., Gupton, A. L., Moffatt, M. E., \& Currie, R. F. (2005). Risk factors for spontaneous preterm birth among Aboriginal and non-Aboriginal women in Manitoba. Paediatric and Perinatal Epidemiology, 19(3), 181-193. doi: 10.1111/j.1365-3016.2005.00644.x 
Li, S., Chen, G., Jaakkola, J. J. K., Williams, G., \& Guo, Y. (2018). Temporal change in the impacts of ambient temperature on preterm birth and stillbirth: Brisbane, 1994-2013. Science of the Total Environment, 634, 579-585. doi: 10.1016/j.scitotenv.2018.03.385

Mathew, S., Mathur, D., Chang, A. B., McDonald, E., Singh, G. R., Nur, D., \& Gerritsen, R. (2017). Examining the effects of ambient temperature on pre-term birth in central Australia. International Journal of Environmental Research and Public Health, 14, 147. doi: 10.3390/ijerph14020147

Morse, J., \& Richards, L. (2002). Read Me First For a User's Guide to Qualitative Methods. Thousand Oaks, California: Sage Publications.

Neggers, Y., Goldenberg, R., Cliver, S., \& Hauth, J. (2004). Effects of domestic violence on preterm birth and low birth weight. Acta Obstetricia et Gynecologica Scandinavica, 83(5), 455-460. doi:10.1111/j.0001-6349.2004.00458.x

Petrou, S., Sach, T., \& Davidson, L. (2001). The long-term costs of preterm birth and low birth weight: results of a systematic review. Child: Care, Health and Development, 27(2), 97-115.

Race, D., Dockery, A. M., Havas, L., Joyce, C., Mathew, S., \& Spandonide, B. (2017). Re-imagining the future of desert Australia: Designing an integrated pathway for enhancing liveability. International Journal of Sustainable Development, 20, 146-165.

Race, D., Mathew, S., Campbell, M., \& Hampton, K. (2016). Understanding climate adaptation investments for communities living in desert Australia: experiences of Indigenous communities. Climatic Change, 139, 461-475. doi: 10.1007/s10584-016-1800-4

Russel, D. J., Zhao, Y., Guthridge, S., Ramjan, M., Jones, M. P., Humphrey, J. S., \& Wakerman, J. (2017). Patterns of resident health workforce turnover and retention in remote communities of the Northern Territory of Australia, 2013-2015. Human Resources for Health, 15(52). doi: 10.1186/ s12960-017-0229-9

Rylander, C., Odland, J. Ø., \& Sandanger, T. M. (2013). Climate change and the potential effects on maternal and pregnancy outcomes: an assessment of the most vulnerable--the mother, fetus, and newborn child. Global health action, 6, 19538. doi:10.3402/gha.v6i0.19538

Shah, P.S., Zao, J., Al-Wassia, H., \& Shah, V. (2011). Pregnancy and Neonatal Outcomes of aboriginal women: a systematic review and meta-analysis. Womens Health Issues, 21, 28-39.

Soilly, A. L., Lejeune, C., Quantin, C., Bejean, S., \& Gouyon, J. B. (2014). Economic analysis of the costs associated with prematurity from a literature review. Public Health, 128, 43-62.

Strand, L.B., Barnett, A.G., \& Tong, S. (2011a). The influence of season and ambient temperature on birth outcomes: A review of the epidemiological literature. Environmental Research, 111, 451-462.

Strand, L.B., Barnett, A.G., \& Tong, S. (2011b). Maternal Exposure to Ambient Temperature and the Risks of Preterm Birth and Stillbirth in Brisbane, Australia. American journal of epidemiology, 175(2), 99-107. doi: 10.1093/aje/kwr404

Ten Hoope-Bender, P., Stenberg, K., \& Sweeny, K. (2016). Reductions in stillbirths-more than a triple return on investment. The Lancet, 387, e14 - e16. doi: 10.1016/S0140-6736(15)01277-5

Trasande, L., Malecha, P., \& Attina T. M. (2016). Particulate Matter Exposure and Preterm Birth: Estimates of US Attributable Burden and Economic Costs. Environmental Health Perspectives, 124, 1913-1918. doi:10.1289/ehp.1510810

Varner, M. W., Silver, R. M., Rowland Hogue, C. J., Willinger, M., Parker, C. B., Thorsten, V. R., ... Reddy, U. M., (2014). Association between stillbirth and illicit drug use and smoking during pregnancy. Obstetrics and Gynecology, 123(1), 113-125. doi: 10.1097/AOG.0000000000000052

Wang, J., Williams, G., Guo, Y., Pan, X., \& Tong, S. (2013). Maternal exposure to heatwave and preterm birth in Brisbane, Australia. BJOG: An International Journal of Obstetrics \& Gynaecology, 120, 1631-1641. 
Webb, L., Clarke, J., Hennessy, K., Heady, C., \& Erwin, T. (2015). Climate Change in Australia 2015. Melbourne, VIC: CSIRO.

Wen, S. W., Smith, G., Yang, Q., \& Walker, M. (2004). Epidemiology of Preterm Birth and Neonatal Outcome. Seminars in Fetal and Neonatal Medicine, 9, 429-435.

WHO (World Health Organization). (2016a). Preterm birth fact sheet. Retrieved from http://www.who.int/ mediacentre/factsheets/fs363/en/

WHO. (2016b). The neglected tragedy of stillbirths. Retrieved from http://www.who.int/ reproductivehealth/topics/maternal_perinatal/stillbirth/Lancet-series/en/

Zhang, Y., Yu, C., \& Wang, L. (2017). Temperature exposure during pregnancy and birth outcomes: An updated systematic review. Environmental Pollution, 225, 700-712. doi: 10.1016/j. envpol.2017.02.066.

\section{Appendix}

Table 1: Semi-structured interview questions

\begin{tabular}{|l|l|}
\hline & Questions \\
\hline 1 & When did you first start working as a midwife? \\
\hline 2 & $\begin{array}{l}\text { For how many years have you been working in Central Australia (Alice Springs hospital } \\
\text { or elsewhere)? }\end{array}$ \\
\hline 3 & $\begin{array}{l}\text { What is your perception on a hot weather definition for Alice Springs (e.g. days above } \\
\left.38^{\circ} \mathrm{C}\right) ? \text { In your experience, do hot summer days impact pregnant women in any way? } \\
\text { We think hot for locals mean 3 days over 38 degrees- what is your impression? }\end{array}$ \\
\hline 4 & $\begin{array}{l}\text { Do you think hot weather while pregnant, impacts on perinatal outcomes? If yes, how? } \\
\text { For example, have you observed any connection between hot weather and preterm } \\
\text { delivery or low birth weight or discomfort or still birth }\end{array}$ \\
\hline 5 & $\begin{array}{l}\text { If you have observed that heat exposure affects pregnant women and or perinatal } \\
\text { outcomes, are they more common in any specific groups? }\end{array}$ \\
\hline 6 & $\begin{array}{l}\text { What advice would you give pregnant women complaining of discomfort because of } \\
\text { heat? }\end{array}$ \\
\hline
\end{tabular}

